\title{
Effect of a hormonal treatment (PMSG and H CG) on primiparous and multiparous sows exhibiting no oestrus after drying-off
}

\author{
Françoise MARTINAT-BOTTE (1), F. BARITEAU ( ${ }^{2}$ ) et P. MALLEON ( \\ (1) I.T.P., I49, rue de Bercy, 75579 Paris Cedex I2 \\ (2) I.N.R.A.-S.E.I.A., $86+80$ Ronille (France) \\ (3) Station de Physiologie de la Reproduction, I.N.R.A., 37380 Nousilly (France)
}

The efficiency of PMSG and HCG hormones was tested in sows which did not exhibit oestrus during the week following the drying off. Three groups were treated (PMSG, PMSG mixed with HCG, PMSG followed by HCG 72 hours later) and compared with a control group. l.ow doses of PMSG (400 I.U.) and of HCG (200 I.U.) were injected on day $9(-2)$ after weaning. Grouping of heats between day 2 and 7 after the treatment $\left(T_{2}-T_{7}\right)$ varied between 50 (PMiSG) and 68 per cent (PMSG and HCG after 72 hours) while, during the same period. only 35.7 per cent of the control sows exhibited heats and were mated. As compared with the controls, the best grouping of farrowings was obtained in the females treated with l'MSG + /and HCG. These farrowings were delayed by 2 to 7 days in comparison with those of the females mated within 9 days after the drying-off. The interest of this technique is discussed in relation with the number of sows (variable according to herds) which did not exhibit oestrus at 9 days.

\section{Reduction of lactation length in the sow. Consequences on reproduction, weight variations and annual productivity}

\author{
A. AUMAITRE et J. P. CARILLETTE \\ Station de Recherches sur l'Elevage des Porcs, \\ I.N.R.A.C.N.R.Z., 78350 Jouy-en-Josas (France)
}

\begin{abstract}
Using a total of 1,916 litters of piglets, two simultaneous experiments were carried out to compare on the one hand, two lactation lengths ( 13 and 38 days) in about 200 sows per treatment and, on the other, three lactation lengths (IO, 2 I and 35 days) in about 125 sows per treatment.

Weaning at io days did not lead to an increase of the weaning-oestrus interval, but a slight lengthening of the weaning-conception interval. Shortening of the lactation length to io or I 3 days significantly reduced the mean size of the subsequent litter $(0,5-0.8$ less $)$. Furthermore, the maximum annual average productivity per sow was determined after weaning at 21 days (24.2 piglets born per sow and per year).

A very high sow effect for the number of animals born alive and for the average weight of piglets at birth was estimated by a hierarchical analysis of variance ( 25 and 43 per cent respectively). On the other hand, the weaning oestrus, weaning-fertilization or farrowing-farrowing interval accounted only for so per cent of the variation in the litter size; hence, the repeatability of these various performances was estimated.

The Ionger the lactation length, the larger the body weight losses of the sows, but the body weight gain during one cycle was the same whatever the lactation length. Thus, body weight variation cannot account for the low prolificacy of the sow in the case of weaning at 10 or 13 days and only the hypothesis of an increase in the embryonic mortality should be retained.

According to our results early weaning of piglets at three weeks might be generalized in pig production units without reducing the fertility of the sow.
\end{abstract}

